\title{
Olivines in main-group pallasites: magma-ocean cumulates or partial melting residues?
}

\section{J.-A. Barrat ${ }^{1,2 *}$, L. Ferrière ${ }^{3}$}

Abstract

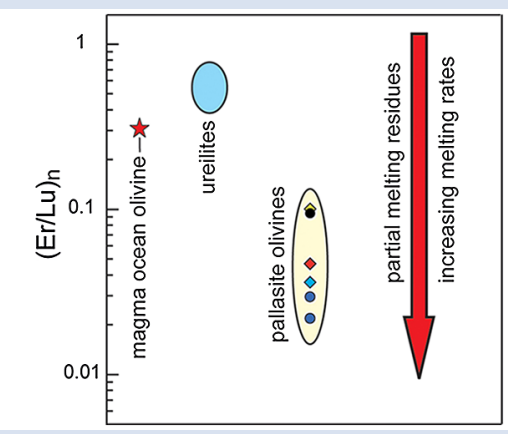

Main-group pallasites (MGPs) are meteorites mainly composed of Fe-Ni metal and olivines, the latter being considered as one of the largest sampling of extraterrestrial mantle material available for study on Earth. We analysed the rare earth element (REE) concentrations of olivines from six MGPs to understand better the processes of formation of their parent mantle. All the investigated samples display very low REE abundances, and enrichments in both light REEs and heavy REEs. We interpret the light REE enrichments as a fingerprint of terrestrial contamination. The least contaminated olivines have higher heavy REE enrichments than those inferred for olivines directly crystallised in a magma ocean. Such enrichments in heavy REEs are possible if the mantle of the MGPs parent body is a residue of partial melting from a chondritic source. Alternatively, re-melting of magma ocean cumulates would explain both the homogeneity of the $\Delta^{17} \mathrm{O}$ values of MGPs, and the heavy REE enrichments of the olivines.

Received 12 August 2020 | Accepted 16 November 2020 | Published 21 January 2021

\section{Introduction}

Some meteorites (achondrites and irons) and samples collected during the Apollo and Luna missions represent materials from a few differentiated bodies, such as the Moon, Mars, and 4-Vesta, but also from other bodies accreted at $4.5 \mathrm{Ga}$, and now disrupted. Many of these samples are magmatic rocks. They are an invaluable source of information to reconstruct the differentiation history of their parent bodies, but also to understand the mechanisms of magma generation. Unfortunately, these rocks only allow an indirect approach to derive their parental mantle compositions and to understand the mantle processes involved in their formation. Among the achondrites, samples of mantles from fully differentiated rocky bodies are very uncommon. An additional source of mantle samples is provided by the pallasites, a relatively rare type of stony-iron meteorites of which about a hundred are known. Pallasites are essentially composed of metal and olivine (i.e. from isolated single crystals and/or polycrystalline aggregates to fragments of "dunitic pebbles"), with variable (low) amount of sulfide (troilite), minor schreibersite, phosphates, and in some cases chromite (e.g., Buseck and Holdsworth, 1977; Scott, 1977). Although only a relatively small number of pallasites are known, their petrographic features and isotopic oxygen compositions show that they originate from at least six distinct parent bodies (e.g., Greenwood et al., 2017). The most abundant ones, the MGPs, represent $\approx 85 \%$ of all the pallasites. They display rather homogenous $\Delta^{17} \mathrm{O}$ values and are thought to derive from one (Greenwood et al., 2006, 2015) or perhaps two parent bodies (Ali et al., 2018).

While pallasites are recognised to be mixtures of mantle and core materials, their formation is still debated (Boesenberg et al., 2012; McKibbin et al., 2019; and references therein). Since the 1960s, they are usually seen as samples of the core-mantle transition zone of a differentiated body (e.g., Anders, 1964; Wasson and Choi, 2003), but this hypothesis has been repeatedly challenged. Although there is no consensus on a precise formation model yet, the variety of textures shown by these meteorites, the diversity of cooling rates recorded by the metal among others, and also geophysical models suggest that the core-mantle mixing is related to catastrophic impacts (e.g., Scott, 1977; Yang et al., 2010; Tarduno et al., 2012; Bryson et al., 2015; Nichols et al., 2016; Walte et al., 2020), or is from an unknown type of volcanism (Johnson et al., 2019). In any case, if the metal is well understood today (e.g., Wasson and Choi, 2003), it is not the case for the mantle fragments and olivines they contain. Some have suggested that mantle fragments could be melting residues after extraction of a large fraction of magma, or alternatively produced by the accumulation of olivines during the crystallisation of a global magma ocean (e.g., Buseck, 1977; Mittlefehldt, 1980; Boesenberg et al., 2012). The latter possibility would be consistent with the observed homogeneity of the $\Delta^{17} \mathrm{O}$ values for olivines which suggest a highly homogeneous or a well homogenised body $\left(\Delta^{17} \mathrm{O}=-0.187 \pm 0.008 \%\right.$ o $(1 \sigma, \mathrm{n}=103)$, Greenwood et al., 2015), however, this is not confirmed by trace

1. Univ. Brest, CNRS, UMR 6538 (Laboratoire Géosciences Océan), Institut Universitaire Européen de la Mer (IUEM), Place Nicolas Copernic, 29280 Plouzané, France

2. Univ. Brest, CNRS, UMR 6539 (Laboratoire des Sciences de l'Environnement Marin), LIA BeBEST, Institut Universitaire Européen de la Mer (IUEM), Place Nicolas Copernic, 29280 Plouzané, France

3. Natural History Museum, Burgring 7, A-1010 Vienna, Austria

* Corresponding author (email: barrat@univ-brest.fr) 
element chemistry data (Mittlefehldt and Herrin, 2010; McKibbin et al., 2013). Therefore, the origin of mantle fragments remains open. Nevertheless, the behaviour of incompatible trace elements, and among them the REEs, should in principle allow their origin to be deciphered. The few pallasite olivines previously analysed showed totally unexpected light REE enrichments (Schmitt et al., 1963, 1964; Masuda, 1968; Saito et al., 1998; Minowa and Ebihara, 2002; Greenwood et al., 2015).

In this study, we analysed a series of olivine fractions and a dunite prepared from six main-group pallasites (samples and methods are described in Supplementary Information; Table S-1), with the aim of explaining the light REE enrichments

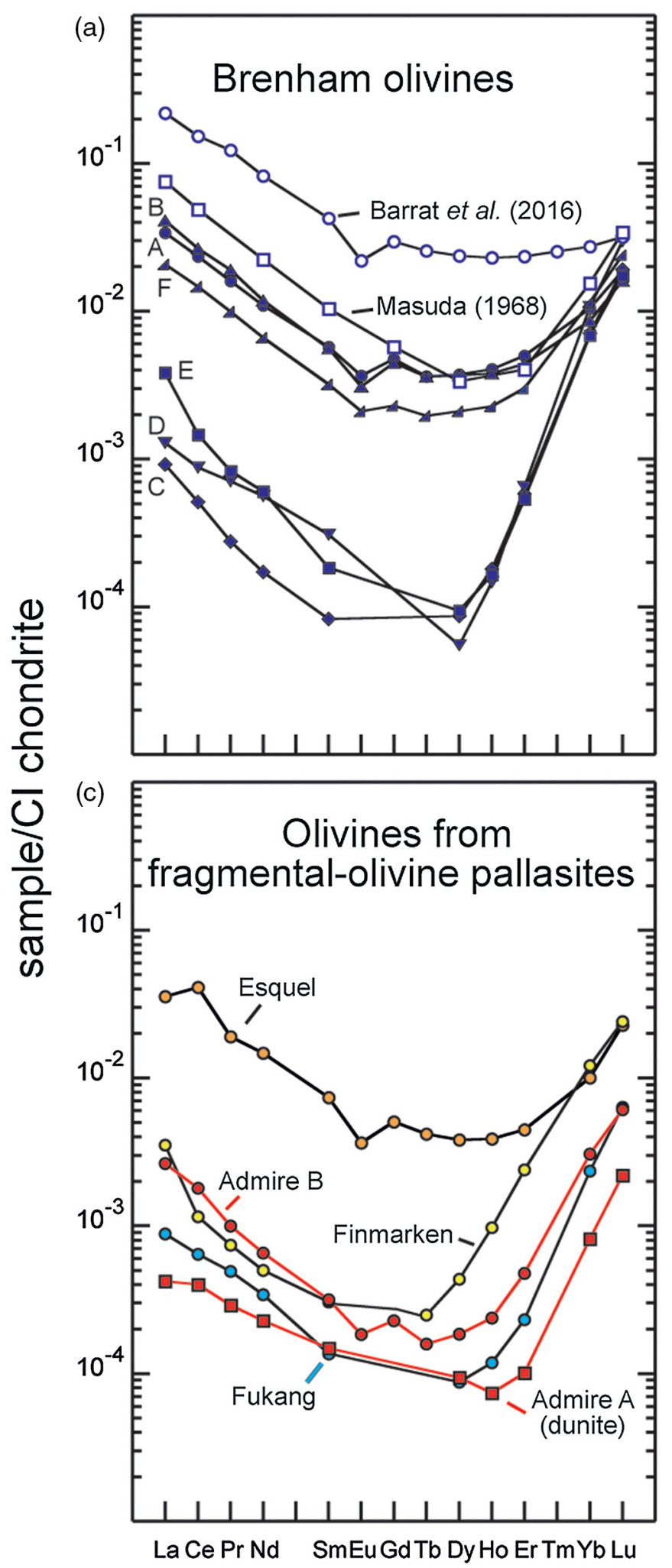

(b)

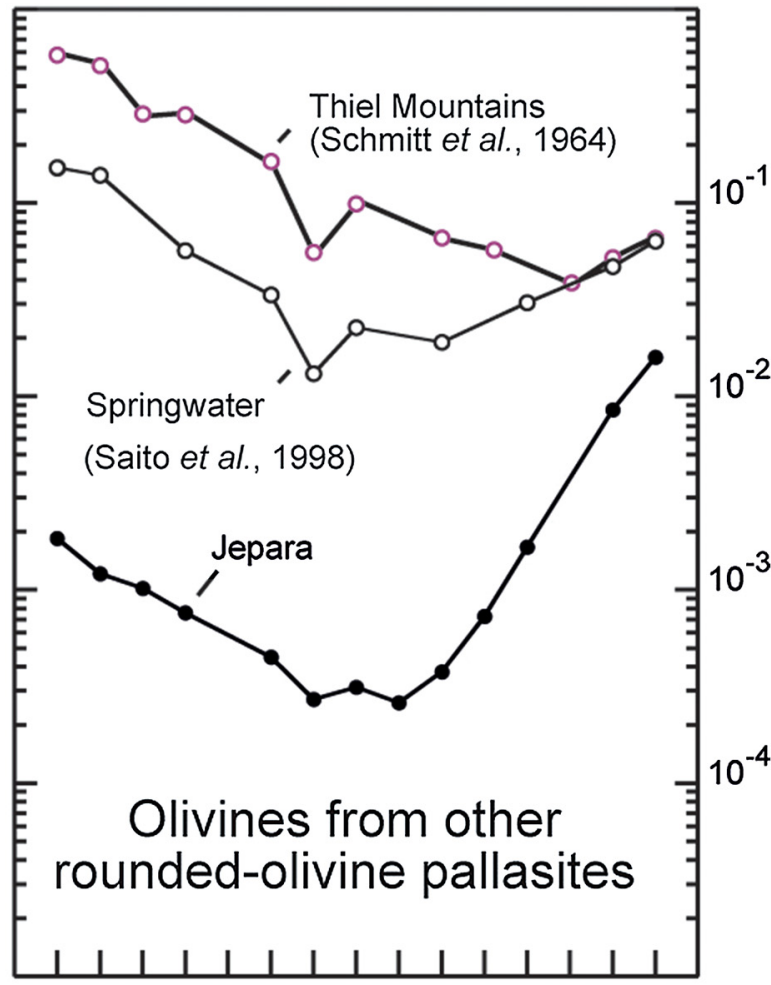

(d)

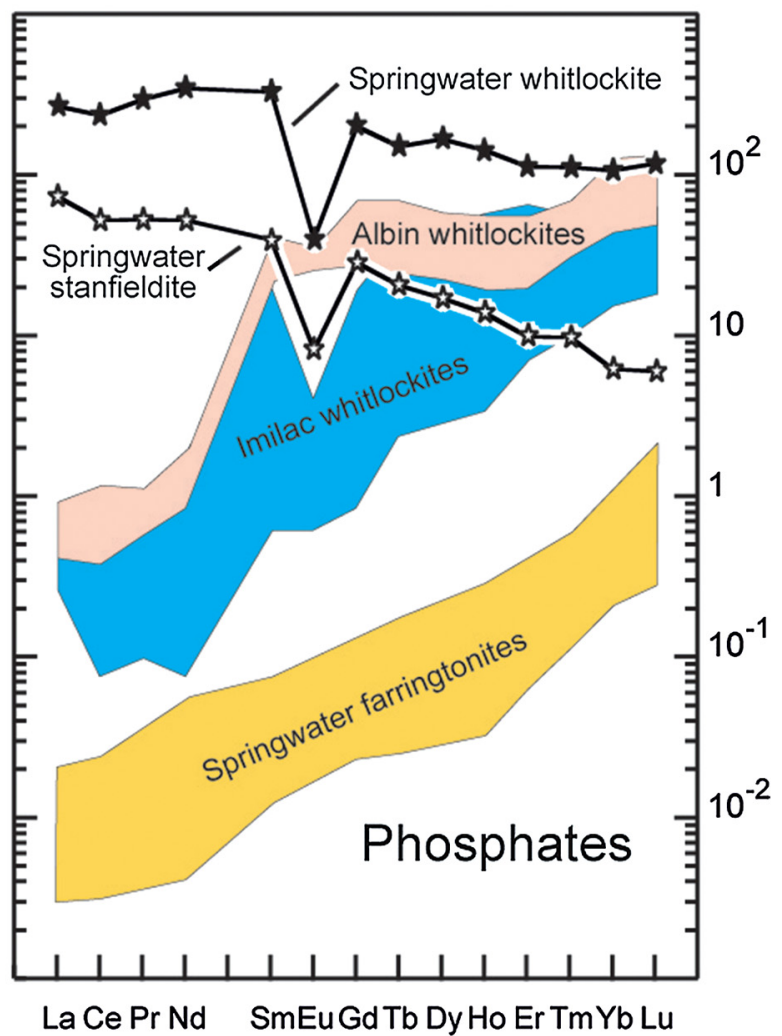

Figure 1 REE patterns of MGP olivines (Schmitt et al., 1963; Masuda, 1968; Saito et al., 1998; Barrat et al., 2016a; and this work) and phosphates (Davis and Olsen, 1991; Hsu, 2003) normalised to Cl chondrite (Barrat et al., 2012). 
described in previous studies, but also to constrain the formation processes of the mantle component contained in pallasites.

\section{Results and Discussion}

Olivine separates were analysed after a very strong leaching step using hot $\mathrm{HCl}$. Results are given in Table S-2. Abundances of Co $(<115 \mu \mathrm{g} / \mathrm{g})$ and $\mathrm{P}(<60 \mu \mathrm{g} / \mathrm{g})$ are low and confirm that our leaching procedure has removed most traces of weathering (such as rust), and adhering traces of metal and/or phosphates. Calcium (from 27 to $281 \mu \mathrm{g} / \mathrm{g}$ ) and Sc (from 0.31 to $2.16 \mu \mathrm{g} / \mathrm{g}$ ) abundances are in the range of reported values for pallasite olivines (e.g., Mittlefehldt, 1980; Hsu, 2003; McKibbin et al., 2013). The REE concentrations in pallasite olivines are low but highly variable, ranging from $6 \times 10^{-5}$ to 0.6 times the $\mathrm{CI}$ abundances (including literature values; Fig. 1). All our samples display U-shaped REE patterns, due to light and heavy REE enrichments $\left[(\mathrm{La} / \mathrm{Lu})_{\mathrm{n}}=\right.$ 0.04-6.9, $\left.(\mathrm{Er} / \mathrm{Lu})_{\mathrm{n}}=0.02-0.74\right]$. Furthermore, the samples displaying the lowest light REE abundances also exhibit the most pronounced heavy REE enrichments (Fig. 1). An excellent relationship is obtained between $(\mathrm{La} / \mathrm{Lu})_{\mathrm{n}}$ and $(\mathrm{Er} / \mathrm{Lu})_{\mathrm{n}}$ ratios (Fig. 2). This is indicative of a mixing line between olivines (with low light REE abundances and heavy REE enrichments [i.e. extremely low Er/Lu ratios]), and another component (or other components) highly enriched in light REEs. This implies that the diversity of REE abundances displayed by the analysed olivines likely simply reflect the presence of impurities which need to be identified.

Among the different phases contained in pallasites, only phosphates and possibly melt inclusions would be rich enough in REEs to affect olivine concentrations. Phosphates in the Springwater pallasite are light REE enriched (Davis and Olsen,
1991), and could explain the shape of the REE pattern displayed by the olivine fraction prepared from this meteorite (Fig. 1; Saito et al., 1998). However, phosphates measured in other pallasites are generally light REE-depleted (Fig. 1), and, therefore, cannot account for the observed mixing line (Figs. 2, 3a). In addition, because we leached our samples before dissolution, and since their P contents are very low (Table S-2), this possibility is very unlikely.

It is known that the presence of a few melt inclusions can significantly change the shape of the REE pattern of an olivine (e.g., Barrat and Bachèlery, 2019). However, unlike in magmatic rocks, the olivines in pallasites are very poor in glassy inclusions. Inclusions composed of tridymite and $\mathrm{Al}, \mathrm{K}$-rich glasses have been described in olivines from the Fukang pallasite (Dellagiustina et al., 2019). Such inclusions are extremely rare, and, thus, it seems difficult to imagine that they could explain the light REE enrichments seen for all pallasite olivines analysed so far.

Alternatively, the light REE enriched end members could be due to terrestrial contamination (Minowa and Ebihara, 2002). Olivines from Esquel (Fig. 1c) show a positive anomaly in Ce $\left(\mathrm{Ce} / \mathrm{Ce}^{*}=1.58\right)$, which is obviously related to some traces of rust not entirely removed by leaching (e.g., Braun et al., 1990). The occurrence of trace amounts of dust or clays in the samples, not removed by leaching, should also be considered. Indeed, the REE patterns of the olivines with the highest REE abundances strongly resemble those of Earth's continental crust rocks. The possibility that all the pallasite olivines analysed to date may be more or less contaminated, either during terrestrial residence time (i.e. weathering, soil contamination, etc.) or during sample preparation, should be seriously considered. We have tested this hypothesis using the mean composition of the

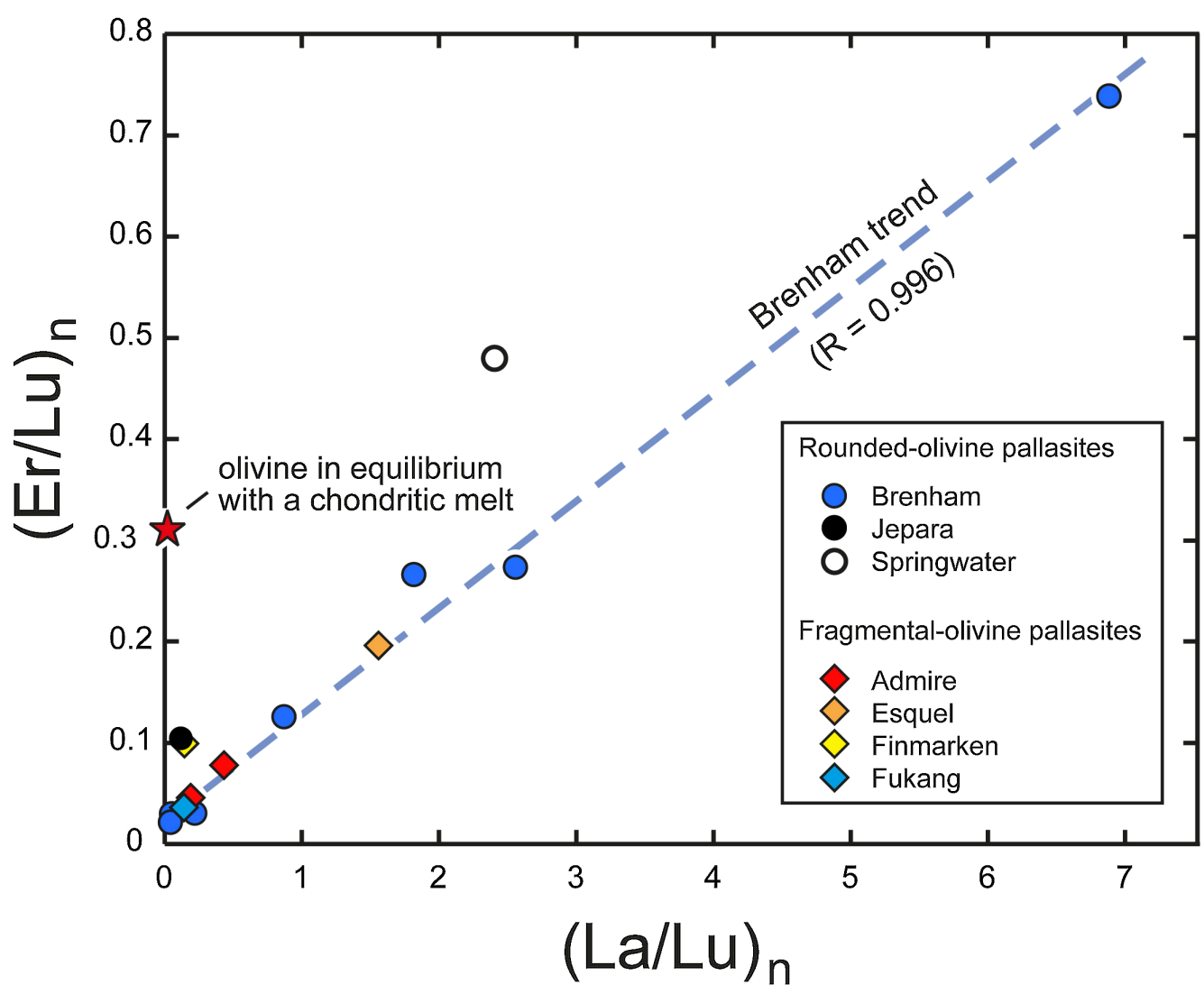

Figure $2(\mathrm{Er} / \mathrm{Lu})_{n}$ vs. (La/Lu $)_{n}$ plot for MGP olivines. Data from Saito et al. (1998), Barrat et al. (2016a), and this work. 

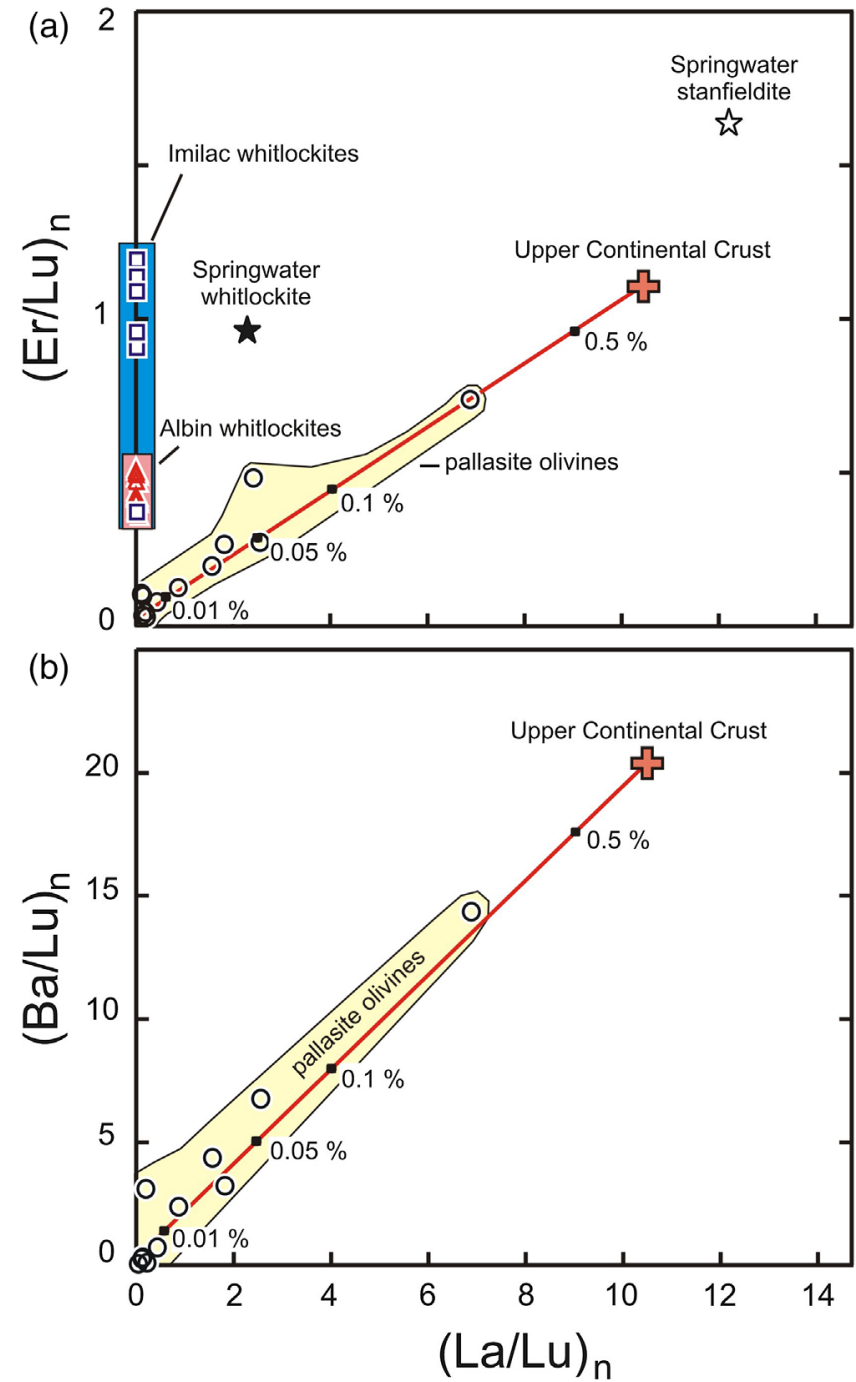

Figure $3(\mathrm{Er} / \mathrm{Lu})_{\mathrm{n}}$ and $(\mathrm{Ba} / \mathrm{Lu})_{\mathrm{n}}$ vs. $(\mathrm{La} / \mathrm{Lu})_{\mathrm{n}}$ plot for MGP olivines. Data from Saito et al. (1998), Greenwood et al. (2015), Barrat et al. (2016a), and this work. Contamination trend uses the average upper continental crust composition from Rudnick and Gao (2014).

terrestrial upper continental crust (Rudnick and Gao, 2014). On the $(\mathrm{Ba} / \mathrm{Lu})_{\mathrm{n}}$ or $(\mathrm{Er} / \mathrm{Lu})_{\mathrm{n}}$ vs. $(\mathrm{La} / \mathrm{Lu})_{\mathrm{n}}$ plots $(\mathrm{Fig} .3)$, the pallasite olivines show a perfect match with the average terrestrial continental crust, strengthening the hypothesis of a contamination. We calculated that the fraction of olivines richest in REEs contain about $0.3 \%$ of terrestrial material, whereas the poorest ones contain below $0.01 \%$ of terrestrial material. Although this terrestrial contribution is extremely limited, it has a huge influence on the concentrations of incompatible elements in olivines.

However, this contamination by a terrestrial component does not mask all the REE features of the olivines, in particular their extremely high heavy REE enrichments (Fig. 2): the least contaminated olivines, from Brenham, are characterised by $(\mathrm{Er} / \mathrm{Lu})_{\mathrm{n}} \leq 0.03, \leq 0.04$ for Fukang, $\leq 0.05$ for Admire, and $\leq 0.10$ for Jepara and Finmarken meteorites. These values place very strong constraints on the formation of the olivines.

Our results allow us to evaluate some of the characteristics of the cumulates produced during the crystallisation of a magma ocean formed in the case of a planetesimal. Although the REE abundances of such a body are unknown, the relative proportions of those elements are certainly chondritic since they were not fractionated by core formation, and are also strongly lithophile. Partition coefficients for olivine are not constant but the ratios of heavy REE partition coefficients vary relatively little. For example, the data obtained by Evans et al. (2008) allow us to calculate that the $\mathrm{D}_{\mathrm{Er}} / \mathrm{D}_{\mathrm{Lu}}$ ratio of olivine is close to 0.3 (see Supplementary Information). The $(\mathrm{Er} / \mathrm{Lu})_{\mathrm{n}}$ ratios of olivines produced during the cooling of a magmatic ocean should be identical. Because the formation of a cumulate is invariably accompanied by magma trapping and possibly subsolidus redistribution, even minute amounts of trapped melt would tend to increase the $\mathrm{Er} / \mathrm{Lu}$ ratio of olivines and of dunitic cumulates (Barrat and Bachelery, 2019). Therefore, the $(\mathrm{Er} / \mathrm{Lu})_{\mathrm{n}}$ ratios of dunites accumulated in a magma ocean cannot be less than $\approx 0.3$.

Nonetheless, the abundances of many trace elements, such as $\mathrm{Ti}, \mathrm{V}, \mathrm{Cr}$ and Ni were significantly modified in olivines during the mixing and cooling with metal (e.g., Hsu et al., 2003), and it is thus questionable whether REE distributions were also affected. We see at least two arguments suggesting that the heavy REE contents of the olivines were preserved. Firstly, REEs, as also $\mathrm{Al}$ and $\mathrm{P}$, diffuse very slowly into olivine. The observed preservation of heterogeneities in $\mathrm{Al}$ and $\mathrm{P}$, and the absence of diffusion profiles for these elements in the olivines (McKibbin et al., 2013) support our hypothesis. Secondly, we have analysed olivines that have undergone different degrees of interaction with the metal (i.e. including a dunite sample, and both angular and rounded olivines), and the least contaminated of these samples are similarly enriched in heavy REEs. Therefore, it is very unlikely that interactions with core material fractionated heavy REEs in olivines.

The $(\mathrm{Er} / \mathrm{Lu})_{\mathrm{n}}$ ratios of pallasite olivines, comprised between 0.03 and 0.1 , are way too different from those estimated for olivines formed in a magma ocean (i.e. $\approx 0.3)$, and, thus, we can rule out this hypothesis. On the other hand, high heavy REE enrichments are an expected characteristic for partial melting residues, and, therefore, for dunites derived from a chondritic precursor (Fig. 4). However, it is impossible to estimate accurately the degree of partial melting of the pallasite mantle. The results are extremely model dependent (initial composition, phase proportions, fractional or dynamic melting, etc.), but in any case require very high melting degrees (probably above $40 \%)$ to account for both the exhaustion of pyroxene and the low heavy REE abundances of the olivines (i.e. Lu concentration ranging from $3.10^{-3}$ to $4.10^{-2} \times \mathrm{CI}$ ). The olivine contained in the main-group pallasites would have to be derived from a mantle even more residual or more refractory than the ureilites, for which melting degrees did not exceed 30 \% (Barrat et al., 2016b).

The very high homogeneity of the $\Delta^{17} \mathrm{O}$ values shown by MGP olivines is however puzzling. One can of course imagine that the parent body was very homogeneous in oxygen isotopes, but such a level of homogeneity, although conceivable, is not observed among any of the different groups of primitive meteorites (Greenwood et al., 2017). It is questionable to what extent the isotopic oxygen composition of the residues is preserved by partial melting. Greenwood et al. (2005) estimated that at melting rates greater than $40 \%$, the $\Delta^{17} \mathrm{O}$ values are homogenised. In the case of fractional melting, or dynamic melting with low porosity, most of the melt is rapidly extracted from the restites, thus limiting the possibility of homogenisation, independent of the level of melting. Although the ureilites did not undergo such high fusion rates, their oxygen isotopic heterogeneities are still very well preserved, illustrating that the ability of partial melting to homogenise the $\Delta^{17} \mathrm{O}$ values was probably overestimated. Thus, if the dunites were derived from chondritic precursors, more variability in $\mathrm{O}$ isotopes would be expected. However, the $\mathrm{O}$ isotopic homogeneity of the main-group pallasites is very comparable to what is observed for the Earth, Moon, Mars, Vesta and the parent body of the angrites, for which magma oceans 


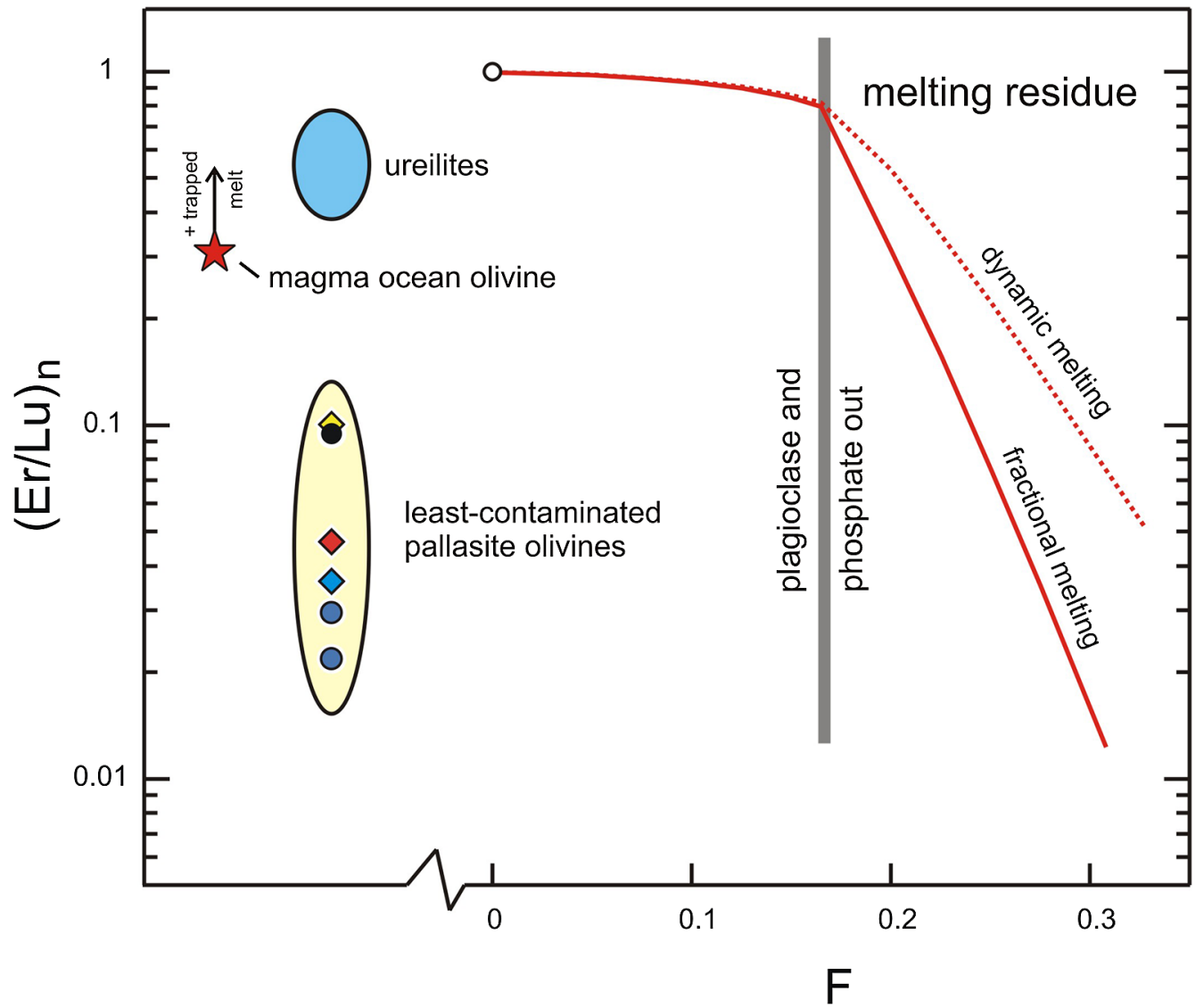

Figure 4 Evolution of the $(\mathrm{Er} / \mathrm{Lu})_{\mathrm{n}}$ ratios in partial melting residues produced from a merrilite-bearing chondrite. Fractional melting and dynamic melting with $\Phi=1 \%$, parameters and partition coefficients are taken from Barrat et al. (2016b). Olivine in equilibrium with a chondritic magma ocean, least contaminated pallasitic olivines (this work), and ureilites (Barrat et al., 2016b) are shown for comparison.

have been considered (Greenwood et al., 2005, 2017). Thus, remelting of ultrabasic cumulates formed in the magma ocean can also lead to dunitic residues characterised by large heavy REE enrichments but also by homogeneous $\Delta^{17} \mathrm{O}$.

While there is no doubt that pallasite olivines derive from a residual mantle, we cannot specify whether this mantle simply formed from the melting of chondrites, or whether its formation was much more complex and involved the crystallisation of a magma ocean, then the melting of the produced cumulates. The homogeneity of the $\Delta^{17} \mathrm{O}$ values displayed by MGPs is, however, in favour of the second hypothesis.

\section{Acknowledgements}

The Brenham olivines were kindly provided by Don Stimpson. We thank Helen Williams for the editorial handling, Claire Nichols and an anonymous reviewer for their constructive comments, and Richard Greenwood for helpful discussions. This work was supported by funds from the Programme National de Planétologie (CNRS-INSU) to the first author.

\section{Editor: Helen Williams}

\section{Additional Information}

Supplementary Information accompanies this letter at https:// www.geochemicalperspectivesletters.org/article2103.

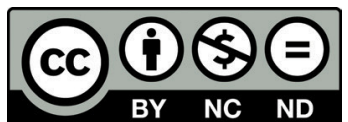

(C) 2021 The Authors. This work is distributed under the Creative Commons Attribution NonCommercial No-Derivatives 4.0 License, which permits unrestricted distribution provided the original author and source are credited. The material may not be adapted (remixed, transformed or built upon) or used for commercial purposes without written permission from the author. Additional information is available at https://www. geochemicalperspectivesletters.org/copyright-and-permissions.

Cite this letter as: Barrat, J.-A. and Ferrière, L. (2021) Olivines in main-group pallasites: magma-ocean cumulates or partial melting residues?. Geochem. Persp. Let. 16, 47-52.

\section{References}

Ali, A., Jabeen, I., Banerjee, N.R., Osinski, G.R., Nicklin I., Gregory, D., Herrmann, P. (2018) The oxygen isotope compositions of olivine in main group (MG) pallasites: New measurements by adopting an improved laser fluorination approach. Meteoritics \& Planetary Science 53, 1223-1237.

ANDERS, E. (1964) Origin, age and composition of meteorites. Space Science Reviews 3, 583-714.

BARRAT, J.A., BAChÉLERY, P. (2019) La Réunion Island dunites as analogs of the Martian chassignites: tracking trapped melts with incompatible trace elements. Lithos 344-345, 452-463.

Barrat, J.A., Zanda, B., Moynier, F., Bollinger, C., Liorzou, C., Bayon, G. (2012) Geochemistry of $\mathrm{CI}$ chondrites: Major and trace elements, and $\mathrm{Cu}$ and $\mathrm{Zn}$ isotopes. Geochimica et Cosmochimica Acta 83, 79-92. 
Barrat, J.A., Dauphas, N., Gillet, P., Boluinger, C, Etoubleau, J., Bischoff, A YAMAGUCHI, A. (2016a) Evidence from Tm anomalies for non-CI refractory lithophile element proportions in terrestrial planets and achondrites. Geochimica et Cosmochimica Acta 176, 1-17.

Barrat, J.A., Jambon, A., Yamaguchi, A., Bischoff, A., Rouget, M.L., Liorzou, C. (2016b) Partial melting of a C-rich asteroid: lithophile trace elements in ureilites. Geochimica et Cosmochimica Acta 194, 163-178.

Boesenberg, J.S., Delaney, J.S., Hewins, R.H. (2012) A petrological and chemical re-examination of Main Group pallasite formation. Geochimica et Cosmochimica Acta 89, 134-158.

Braun, J.J., Pagel, M., Muller, J.P., Bilong, P., Michard, A., Guillet, B. (1990) Cerium anomalies in lateritic profiles. Geochimica et Cosmochimica Acta 54, 781-795

Bryson, J.F.J., Nichols, C.I.O., Herrero-Albillos, J., Fronast, F., Kasamas, T., Alimadadi, H., van der Laan, G., Nimmo, F., Harrison, R.J. (2015) Longlived magnetism from solidification-driven convection on the pallasite parent body. Nature 517, 472-475.

BUSECK, P.R. (1977) Pallasite meteorites - mineralogy, petrology and geochemistry. Geochimica et Cosmochimica Acta 41, 711-740.

BuseCK, P.R., Holdsworth, E. (1977) Phosphate minerals in pallasites meteorites. Mineralogical Magazine 41, 91-102.

DAVIS, A.M., OlsEN, E.J. (1991) Phosphates in pallasites meteorites as probes of mantle processes in small planetary bodies. Nature 353, 637-640.

Dellagiustina, D.N., Habib, N., DomaniK, K.J., Hill, D.H., LauretTa, D.S Goreva, Y.S., Killgore, M., Hexiong, Y., Downs, R.T. (2019) The Fukang pallasite: Characterization and implications for the history of the Maingroup parent body. Meteoritics \& Planetary Science 54, 1781-1807.

Evans, T.M., O’Neill, H.St.C., Tuff, J. (2008) The influence of melt composition on the partitioning of REEs, Y, Sc, Zr and Al between forsterite and melt in the system CMAS. Geochimica et Cosmochimica 72, 5708-5721.

Greenwood, R.C., Franchi, I.A., Jambon, A., Buchanan, P. (2005) Widespread magma oceans on asteroidal bodies in the early solar system. Nature 435, 916-918.

GreenWood, R.C., Franchi, I.A., Jambon, A., Barrat, J.A., Burbine, T.H. (2006) Oxygen isotope variation in stony-iron meteorites. Science 313, 1763-1765.

GreenWOOD, R.C., BarRat, J.A., SCOTt, E.R.D., HAACK, H., BuCHANAN, P.C., Franchi, I.A., Yamaguchi, A., Johnson, D., Bevan, A.W.R., Burbine, T.H. (2015) Geochemistry and oxygen isotope composition of main-group pallasites and olivine-rich clasts in mesosiderites: Implications for the "Great Dunite Shortage" and HED-mesosiderite connection. Geochimica et Cosmochimica Acta 169, 115-136.

Greenwood, R.C., Burbine, T.H., Miller, M.F., Franchi, I.A. (2017) Melting and differentiation of early-formed asteroids: The perspective from high precision oxygen isotope studies. Chemie der Erde 77, 1-43.

Hsu, W. (2003) Minor element zoning and trace element geochemistry of pallasites. Meteoritics \& Planetary Science 38, 1217-1241.

Johnson, B.C., Sori, M.M., Evans, A.J. (2019) Ferrovolcanism on metal worlds and the origin of pallasites. Nature Astronomy 4, 41-44.

MASUDA, A. (1968) Lanthanide concentrations in the olivine phase of the Brenham pallasite. Earth and Planetary Science Letters 5, 59-62.

McKibin, S.J., O’Neill, H.St.C., Mallmann, G., Halfpenny, A. (2013) LA-ICP-MS mapping of olivine from the Brahin and Brenham meteorites: Complex elemental distributions in the pallasite olivine precursor. Geochimica et Cosmochimica Acta 119, 1-17.

McKibiin, S.J., Pittarello, L., Makarona, C., Hamann, C., Hecht, L., Chernonozhrin, S.M., Goderis, S., Clayes, P. (2019) Petrogenesis of main group pallasite meteorites based on relationships among texture, mineral ogy, and geochemistry. Meteoritics \& Planetary Science 54, 2814-2844.

MinOWa, H., EBIHARA, M. (2002) Rare Earth Elements in pallasite olivines. Lunar and Planetary Science XXXIII. Lunar and Planetary Institute, Houston, \#1386 (abstr.).

Mittlefehldt, D.W. (1980) The composition of mesosiderite olivine clasts and implications for the origin of pallasites. Earth and Planetary Science Letters 51, 29-40.

MitTLEFEhLdT, D.W., HeRRIN, J.S. (2010) Trace element compositions of pallasite olivine grains and pallasite origin. Meteoritical Society Meeting 73, \#5386 (abstr.).

Nichols, C.I.O., Bryson, J.F.J., Herrero-Albillos, J., Kronast, F., Nimmo, F., HARRISON, R.J. (2016) Pallasite paleomagnetism: quiescence of a core dynamo. Earth and Planetary Science Letters 441, 103-112.

Rudnick, R.L., GaO, S. (2014) 4.1 - Composition of the Continental Crust. In: Holland, H.D., Turekian, K.K. (Eds.) Treatise on Geochemistry (Second Edition) Elsevier, Oxford, 1-51.
SAITo, T., Shimizu, H., Masuda, A. (1998) Experimental study of major and trace element partitioning among olivine, metallic phase and silicate melt using chondrite as starting material: implications for V-shaped REE patterns of the pallasites meteorites. Geochemical Journal 32, 159-182.

Sсотт, E.R.D. (1977) Formation of olivine-metal textures in pallasite meteorites. Geochimica et Cosmochimica Acta 41, 693-710.

Schmitt, R.A., Smith, R.H., Lasch, J.E., Mosen, A.W., Olehy, D.A., Vasilevskis, J (1963) Abundances of the fourteen rare-earth elements, scandium, and yttrium in meteoritic and terrestrial matter. Geochimica et Cosmochimica Acta 27, 577-622.

Schmitt, R.A., Smith, R.H., Olehy, D.A. (1964) Rare-earth, yttrium and scandium abundances in meteoritic and terrestrial matter-II. Geochimica et Cosmochimica Acta 28, 67-86.

Tarduno, J.A., Cottrell, R.D., Nimmo, F., Hopkins, J., Voronov, J., Erickson, A., Blackman, E., Scott, E.R.D., McKinley, R. (2012) Evidence for a dynamo in the main group pallasite parent body. Science 338, 939-942.

Walte, N.P., Solferino, G.F.D., Golabek, G.J., Souza, D.S., Bouvier, A. (2020) Twostage formation of pallasites and the evolution of their parent bodies revealed by deformation experiments. Earth and Planetary Science Letters 546,116419

WAsson, J.T., ChOI, B.-G. (2003) Main-group pallasites, chemical composition, relationship to IIIAB irons, and origin. Geochimica et Cosmochimica Acta 67, 3079-3096.

YANG, J., Goldstein, J.I., ScotT, E.R.D. (2010) Main-group pallasites: thermal history, relationship to IIIAB irons, and origin. Geochimica et Cosmochimica Acta 74, 4471-4492. 